\title{
Letter to Editor Regarding the Article Entitled "Impact of Sensory Stimulation on Pharyngo-esophageal Swallowing Biomechanics in Adults with Dysphagia: A High-Resolution Manometry Study"
}

\author{
Shahryar Zainaee ${ }^{1}$ (D) \\ Received: 12 November 2020 / Accepted: 23 June 2021 / Published online: 2 July 2021 \\ (c) The Author(s), under exclusive licence to Springer Science+Business Media, LLC, part of Springer Nature 2021
}

\begin{abstract}
In accordance with the abstract as well as results of the article entitled "Impact of Sensory Stimulation on Pharyngo-esophageal Swallowing Biomechanics in Adults with Dysphagia: A High-Resolution Manometry Study" published in Dysphagia journal, it has been found the cold bolus significantly reduced extent of upper esophageal sphincter opening during swallowing as measured by Integrated Relaxation Pressure from 9.34 to $5.17 \mathrm{mmHg}$. But, contrarily, it is written in paragraph four of the discussion that "interestingly, only the cold bolus significantly increased the extent of upper esophageal sphincter opening in this study based on the Integrated Relaxation Pressure metric" which considerably contrasts with the result of the study.
\end{abstract}

Keywords Sensory stimulation · Pharyngo-esophageal swallowing · Dysphagia $\cdot$ High-resolution manometry $\cdot$ Deglutition · Cold stimulation

To the editor,

I am writing to inform an important error took place in article entitled "Impact of Sensory Stimulation on Pharyngoesophageal Swallowing Biomechanics in Adults with Dysphagia: A High-Resolution Manometry Study" which was published in Dysphagia journal on 01 January 2020 (Volume 35, issue 5) [1].

According to the abstract and results of this article, it has been found the cold bolus significantly reduced extent of upper esophageal sphincter (UES) opening during swallowing as measured by Integrated Relaxation Pressure (IRP) from 9.34 to $5.17 \mathrm{mmHg}$ ( $p=0.032$; 95\% CI 0.39-7.97). But, contrarily, it is written in paragraph four of the discussion that "interestingly, only the cold bolus significantly increased the extent of UES opening in this study based on the IRP metric" which considerably contrasts with the result of the study.

\section{Reference}

1. Regan J. Impact of sensory stimulation on pharyngo-esophageal swallowing biomechanics in adults with dysphagia: a high-resolution manometry study. Dysphagia. 2020;35(5):825-33.

Publisher's Note Springer Nature remains neutral with regard to jurisdictional claims in published maps and institutional affiliations.
Shahryar Zainaee

hamidzne.9499@gmail.com

1 Department of Speech therapy, Paramedical School, Mashhad University of Medical Sciences, Mashhad, Iran 